\title{
A Review and Prospect of Numerical Simulation of Complex Hydraulic Fracture Propagation in Unconventional Reservoirs
}

\author{
Xiaogang $\mathrm{Li}^{1,2}$, Changyin $\mathrm{Liu}^{1}$, Liangping $\mathrm{Yi}^{2, *}$, Zhiyu Sun ${ }^{1}$ and Zhaozhong Yang ${ }^{2}$ \\ ${ }^{1}$ State Key Laboratory of shale oil gas accumulation mechanism and effective development, SINOPEC Beijing 100083, China \\ ${ }^{2}$ Petroleum and Natural Gas Engineering Institute, Southwest Petroleum University, Xindu Avenue 8, 610500 Chengdu, China \\ *Corresponding author
}

\begin{abstract}
Due to unconventional reservoir have natural weak discontinuities such as natural fractures and bedding planes, the hydraulic fracture has complicated fracture network morphology. Therefore, the traditional fracturing design method and the numerical simulation method of fracture propagation were restricted in the unconventional reservoir. In this paper, the application of the extended finite element method(XFEM), discrete element method(DEM), and displacement discontinuity method(DDM) in the simulation of hydraulic fracturing are discussed, as well as their advantages and disadvantages. It is indicated that XFEM and DEM have strong advantage in small scale mechanism analysis, while DDM has the superiority in the simulation of actual fracturing process in homogeneous formation. Finally, we draw the conclusion that combining two or more numerical simulation methods to simulate the fracture propagation of unconventional reservoirs will be a promising direction.
\end{abstract}

Keywords-unconventional reservoirs; hydraulic propagation; extended finite element method; discrete element method; displacement discontinuity method

\section{INTRODUCTION}

With the development of global industry, the demand for oil and gas is increasing. Unconventional oil and gas(shale oil and gas, coalbed methane, tight sandstone oil and gas ) has received more and more attention because its large amount of resources and wide distribution[1-4]. The porosity and permeability of unconventional reservoirs are extremely low. To improve the single well-controlled reserves and productivity, hydraulic fracturing have been widely used in such formations[5-8]. Different from conventional reservoirs fracturing to form a single fracture, unconventional reservoirs contains a large number of natural fractures, therefore, the hydraulic fracture morphology in this reservoirs is complex network. At present, the following three numerical simulation methods are most widely used to simulate the complex fracture propagation:(1) Extended Finite Element Method(XFEM);(2) Discrete Element Method( DEM);(3) Displacement Discontinuity Method (DDM).Therefore, the advantages and limitations of this three methods and prospect of complex fracture propagation simulation method are analyzed in this paper.

\section{COMPLEX Fracture Propagation SimUlation METHOD}

\section{A. Extended Finite Element Method}

The extended finite element method is an improved method based on the conventional finite element method. In this improved approach, mesh boundary does not need to coincide with fracture surfaces, and the fracture surfaces are presented by modifying approximation or constitutive relation of the elements, therefore, fractures propagate are independent of mesh configuration[9]. Lecampion et al.[10] first adopted the extended finite element method to simulate the hydraulic fracture extension under the condition of linear elastic deformation. Ren et al. [11] presented an XFEM algorithm for hydraulic fracturing analysis with considering water pressure on the crack surface. Zhou et al. [12] combined the XFEM and the finite volume methods to model hydraulic-driven fractures with arbitrary orientation in tight gas reservoirs. Sheng and $\mathrm{Li}[13]$ proposed a numerical scheme to simulate the hydraulic fracture propagation in a frame by the XFEM, the fracture faces are treated as internal boundaries, which are opened and supported by hydraulic pressure. Zeng and Yao[14] developed a hydraulic fracture propagation numerical scheme that the crack flow field and the rock stress field were solved with the finite element method and the XFEM respectively, and the two fields were coupled through the Picard iteration. Lamb et al. $[15,16]$ combined XFEM with the dual-porosity and dualpermeability model to describe the fluid flow, deformation, and fracture propagation in fractured porous medium. Mohammadnejad and Khoei[17] carried out a extended finite element modeling of cohesive crack propagation in multiphase porous media. Then Mohammadnejad and Khoei[18] subsequently proposed a fully coupled numerical model for the modeling of the hydraulic fracture propagation in porous media using the XFEM in conjunction with the cohesive crack model, there model not need to introduce leak-off coefficient to describe the fluid leak-off phenomenon. Liu et al. [19] presented a fully coupled (flow and mechanics) hydraulic fracture propagation model based on the XFEM to account for the sequential and simultaneous propagation of nonplanar fractures. Wang et al. [20] established a 2D fully coupled pore pressure-stress plane strain model based on the XFEM in conjunction with cohesive zone method. But Liu[19] and 
Wang[20] models are both established in ABAQUS finite element commercial software.

However, the above researches did not consider the effect of natural fractures. But the unconventional reservoirs contains abundant of natural fractures, therefore, Shi and $\mathrm{Yu}$ [21] presented a multiple fracture growth model based on the $\mathrm{XFEM}$,in their model the fracture junction is analyzed using the junction enrichment function, and the generalized nodal shape functions are used in a cluster of nodes around the fractures, a ramp function is used to avoid the blending element problem. Taleghani and Olson[22,23] developed an XFEM algorithm to simulate fracture propagation, initiation and intersection in fractured reservoirs. Their results show that the natural fractures has significant impact on hydraulic fracture trajectory, length, width and proppant transport, especially under the condition of high stress heterogeneity.

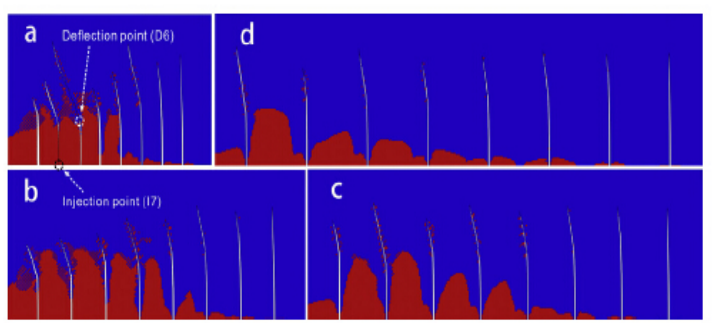

FIGURE I. SIMULATION OF FRACTURE PROPAGATION BASED ON XFEM [19]

\section{B. Discrete Element Method}

The DEM is a new numerical method first proposed by Cundall in 1971[24]. The biggest difference between DEM with other numerical method are that DEM allows block unit occur large displacement motion (including rotation), or even completely separated from each other, and the calculation process does not need to meet the requirements of deformation coordination equation and displacement continuity equation.

Zhao et al. [25] simulated the interaction between hydraulic fractures and natural fractures by using two dimensional discrete element method, the process of cohesive particles rupture is considered as new fracture formation in their simulation. Zangeneh et al. [26] used DEM to study the influence of natural fractures and in-situ stress on the hydraulic fracture propagation, in order to simulate the complex hydraulic fractures extension process, the Voronoi unstructured grid with higher flexibility is used in the grid. Their model can accurately simulate the natural fractures tensile and shear failure under the influence of hydraulic fractures. Nagel et al. [27] study the initiation and propagation of hydraulic fracture in a reservoir with natural fractures based on the threedimensional discrete element method. Their research show that the tensile rupture occurred mainly in the hydraulic fracture surface, and shear rupture mainly along natural fractures surface. Hamidi et al. [28] presented an three-dimensional discrete element algorithm to simulate hydraulic fracture initiation and extension , their research indicate that the success of hydraulic fracturing not only depends on the construction parameters, such as fracturing fluid properties and injection rate, but also depends on the in-situ stress and rock properties. $\mathrm{Su}$ [29] comparatively analyzed fracture networks propagation configuration of single well fracturing and hydraulically maximizing fracture networks fracturing based on discrete element method, proving that increasing stimulated reservoir volume by hydraulically maximizing fracture networks fracturing technique of vertical coalbed methane wells is feasible. $\mathrm{Lu}[30$ ] adopted a 3D discrete element software (3DEC) to study the influence of construction parameters, insitu stress, and cleat properties on the complex multi-fracture propagation. Zhao et al. [31] established a fracture network expansion model by combining finite element method and discrete element method, in their model the finite element method is used to solve the deformation of the block, and the discrete element method is used to simulate fracture formation.

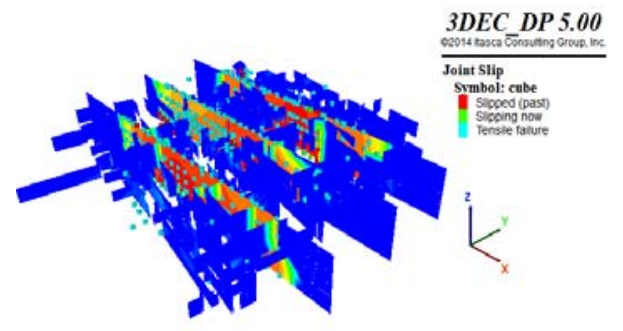

FIGURE II. SIMULATION OF FRACTURE PROPAGATION BASED ON DEM [30]

\section{Displacement Discontinuity Method}

The XFEM and DEM need to discrete the whole calculation area into numerous elements, however, the displacement discontinuity method only need to discrete the fracture surface into a certain number of units, and then establish the algebraic equations which can satisfy the stress or displacement boundary[32,33]. This method can reduce the calculation area dimension, so reduce the computation greatly.

Olson[34,35] adopted the displacement discontinuity method to simulate interaction of multi-cluster hydraulic fracture and natural fracture. Their studies indicated that there are two mainly factors influence on the stimulated reservoir volume, the one is the angle between hydraulic fracture and natural fracture, the other is the fracture net pressure. Based on the Olson's model,Wu and Olson[36,37] established a coupling model for simultaneous multiple-fracture propagation within a stage in horizontal well .In their model, stress interference among fractures and fracture width are calculated by DDM, the control equation of fracturing fluid flowing in wellbore, perforation and hydraulic fracture are established based on hydromechanics and hydraulic fracturing mechanics. In addition, the Newton iteration and Picard iteration are used to solve the coupled equations of fluid flow and fracture deformation. Zhao et al.[38] coupling elastic deformation of rock, stress interaction among fractures, fluid flow in fractures and flow distribution into different fractures to establish a simultaneous propagation of multiple hydraulic fractures in horizontal wells based on DDM. Guo et al.[39] in order to understand the impact of stress interference caused by the artificial open cracks on the formation of complex fractures of subsequent fracturing, and to guide the optimal design of shale fracturing,a model of stress interference of artificial fractures was established based on the DDM. 


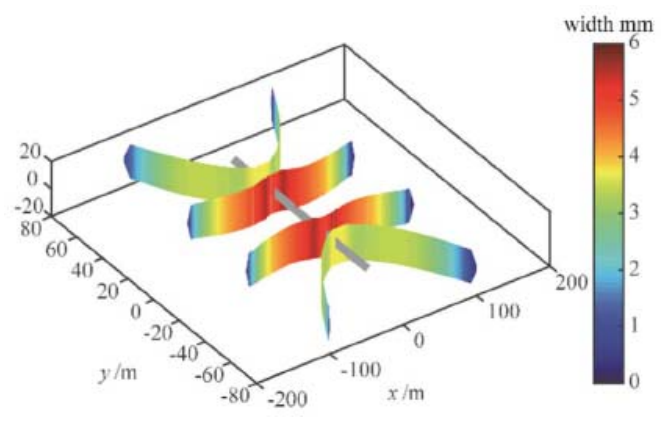

FIGURE III. SIMULATION OF FRACTURE PROPAGATION BASED ON DDM[38]

\section{METHODS COMPARISON AND PROSPECT}

- $\quad$ The XFEM, DEM and DDM have their own advantages and disadvantages. Specifically, the XFEM needs to discrete the whole calculation area into numerous elements and aggregate the stiffness matrix at each expansion step, so the calculation is much bigger than that of the DDM in the simulation of hydraulic fracture propagation . Another disadvantage is that it is difficult to determine the enriched function of the intersecting elements after the intersection of hydraulic fractures and natural fractures. In addition, due to the enriched functions are added to describe the fracture element, the stiffness matrix is ill conditioned, so there is a certain error in the solution. However, it is of great advantage to use the XFEM to simulate fracture propagation in heterogeneous medium, because this method can clearly describe any point mechanical properties of the calculation area.

- $\quad$ Due to the DEM need to discrete the computational domain into blocks, each calculation step needs to determine the relative position between the blocks, and repeated iterative calculating to satisfy the equilibrium equations, so the computation is bigger than that of XFEM and DDM. Besides, fracture can only extend along the predefined discrete network boundaries. But in the DEM, the elements can be contacted with each other and can be separated from each other, therefore, the DEM has advantages in simulating the tensile and shear failure process of rock, and the large deformation process of rock.

- Compared with the XFEM and DEM, the biggest advantage of the DDM is that it is not need to discrete the whole computational domain, but only to discrete the fracture boundary, therefore, the calculation is greatly reduced. However, DDM can only be used in homogeneous formation.

In conclusion, XFEM and DEM have strong advantage in small scale mechanism analysis, while DDM has the superiority in the simulation of actual fracturing process in homogeneous formation. Therefore, it is a promising research direction to combining two or more numerical simulation methods to simulate the fracture propagation of unconventional reservoirs.

\section{ACKNOWLEDGMENT}

The research is supported by the National Science and Technology Major Project of China (2016ZX05002-005-0011), Open funds of State Key Laboratory of shale oil gas accumulation mechanism and effective developmentt (G580015-ZS-WX042)

\section{REFERENCES}

[1] Jia Chengzao, Zheng Min,Zhang Yongfeng. Unconventional hydrocarbon resources in China and the prospect of exploration and development[J]. Petroleum Exploration and Development,2012,39(2):129-136.

[2] Zou Caineng,Dong Dazhong,Yang Hua,et al. Conditions of shale gas accumulation and exploration practices in China $[\mathrm{J}]$. NaturalGas Industry,2011,31(12):26-39.

[3] Zou Caineng,Dong Dazhong,Wang Shejiao,et al. Geological characteristics,formation mechanism and resource potential of shale gas in China $[\mathrm{J}]$. Petroleum Exploration and Development,2010,37(6):641-653.

[4] Dong Dazhong,Zou Caineng,Yang Hua,et al. Progress and prospects of shale gas exploration and development in China $[\mathrm{J}]$. Acta Petrolei Sinica,2012,33(1):107-114.

[5] George E K.Thirty years of gas shale fracturing:what have we learned [R. SPE 133456, 2010.

[6] Wu Qi, Xu Yun , Wang Tengfei ,et al.The revolution of reservoir stimulation :An introduction of volume fracturing[J] Natural Gas Industry,2011,31(4):7 12.

[7] LI Xiaogang, LUO Dan, LI Yu, et al. Advances of Mechanism Study of Fracture Networks Formed by Simultaneous Fracturing Process[J]. XINJIANG PETROLEUM GEOLOGY, 2013,34(02):228-231.

[8] WANG Haitao, JIANG Tingxue, LI Yuanzhao,et al.Method for Fracturing Stage and Cluster Optimization in Shale Gas Horizontal Well[J]. XINJIANG PETROLEUM GEOLOGY, 2016,37(02):218-221.

[9] Moes N, Dolbow J, Belytschko T. A finite element method for crack growth without remeshing[J]. International Journal for Numerical Methods in Engineering. 1999,46:131-150.

[10] Lecampion B, Detournay E. An implicit algorithm for the propagation of a hydraulic fracture with a fluid lag[J]. Computer Methods in Applied Mechanics and Engineering. 2007,196:49-52.

[11] REN QW, DONG YW,YU TT. Numerical modeling of concrete hydraulic fracturing with extended finite element method[J]. Science in China. Series E: Technological Sciences 2009,52: 559-565.

[12] Zhou L, Gou Y, Hou ZM, et al. Numerical modeling and investigation of fracture propagation with arbitrary orientation through fluid injection in tight gas reservoirs with combined XFEM and FVM[J]. Environ Earth Sci .2015,73: 5801-5813.

[13] SHENG Mao , LI Gen-sheng. EXTENDED FINITE ELEMENT MODELING OF HYDRAULIC FRACTURE PROPAGATION[J]. ENGINEERING MECHANICS, 2014,31(10):123-128.

[14] ZENG Qing- dong,YAO Jun. Numerical Simulation of Shale Hydraulic Fracturing Based on the Extended Finite Element Method[J]. Applied Mathematics and Mechanics,2014,35(11):1239-1248.

[15] Lamb A R, Gorman G J, Gosselin O R, et al. Coupled deformation and fluid flow in fractured porous media using dual permeability and explicity definrd fracture geometry[C]. SPE EUROPEC/EAGE Annual Conference and Exhibition, 2010, SPE-131725-MS:1-15.

[16] Lamb A R, Gorman G J, Elsworth D. A fracture mapping and extended finite element scheme for coupled deformation and fluid flow in fractured porous media[J].International Journal for Numerical and Analytical Methods in Geomechanics, 2013, 37:2916-2936.

[17] Mohammadnejad.T , Khoei A. R. Hydro-mechanical modeling of cohesive crack propagation in multiphase porous media using the extended finite element method[J]. Int. J. Numer. Anal. Meth. Geomech2013, 37:1247-1279.

[18] Mohammadnejad.T, Khoei A. R. An extended finite element method for hydraulic fracture propagation in deformable porous media with the 
cohesive crack model[J]. Finite Elements in Analysis and Design,2013,73:77-95.

[19] Liu C, Wang XL , Deng DW, et al. Optimal spacing of sequential and simultaneous fracturing in horizontal well[J]. Journal of Natural Gas Science and Engineering ,2016,29:329-336.

[20] Wang XL, Liu C, Wang H, et al. Comparison of consecutive and alternate hydraulic fracturing in horizontal wells using XFEM-based cohesive zone method[J].Journal of Petroleum Science and Engineering,2016,143:14-25.

[21] SHI Lu-yang,YU Tian-tang. Analysis of multiple crack growth using extended finite element method[J]. Rock and Soil Mechanics,2014,35(1):263-272.

[22] Taleghani A D. Fracture re-initiation as a possible branching mechanism during hydraulic fracturing [C]. ARMA 10-278,2010.

[23] Taleghani A D, Olson J E. Numerical modeling of multi-stranded hydraulic fracture propagation: accounting for the interaction between induced and natural fractures[J].SPE Journal,2011,16(3):575-581.

[24] Gundall P A.A computer model for simulating progressive large scale movement in block rock system[J].Symposium ISRM,1971,Proc 2:129136.

[25] Zhao X P, Young R P. Numerical simulation of seismicity induced by hydraulic fracturing in naturally fractured reservoirs[C]. SPE Annual Technical Conference and Exhibition. Society of Petroleum Engineers, 2009.

[26] Zangeneh N, Eberhardt E, Bustin R M. Application of the distinctelement method to investigate the influence of natural fractures and insitu stresses on hydrofrac propagation[C].ARMA12-223,2012.

[27] Nagel N, Gil I, Sanchez-Nagel M. Simulating Hydraulic Fracturing in Real Fractured Rocks-Overcoming the Limits of Pseudo3D Models[C]. Paper SPE 140480 presented at the SPE Hydraulic Fracturing Technology Conference, The Woodlands, Texas, 24-26 January 2011.

[28] Hamidi F, Mortazavi A. A New Three Dimensional Approach to Numerically Model Hydraulic Fracturing Process[J]. Journal of Petroleum Science and Engineering, 2014, 124: 451-467.

[29] Su Zhou. Feasibility study of hydraulically maximizing fracture networks fracturing of vertical coalbed methane wells[D].CHENG Du: Southwest Petroleum University,2015.

[30] Lu Yanjun. MECHANISM RESEARCHES OF STIMULATED RESERVOIR VOLUME IN COAL SEAMS[D].CHENG Du: Southwest Petroleum University,2015.

[31] ZHAO Zhenfeng, WANG Wenxiong, ZOU Yushi,et al. Numerical Simulation Research of Fracture Propagation in Tight Sand Reservoir by Volume Fracturing Process[J]. XINJIANG PETROLEUM GEOLOGY,2014,35(4):447-451.

[32] Crouch SL. Solution of plane elasticity problems by the displacement discontinuity method[J].Int.J.Numer.Methods Eng.1976,10:301-343.

[33] Crouch SL, Starfield AM. Boundary element methods in solid mechanics[M].Goerge Allen and Unwin Publishers,1983.

[34] Olson J E. Multi-fracture propagation modeling: applications to hydraulic fracturing in shales and tight gas sands[C]. Paper ARMA 08327 presented at The 42th U.S. Rock Mechanics Symposium (USRMS) held in San Francisco, California, 29 June-2 July, 2008: 1-8.

[35] Olson J E, Dahi-Taleghani A. Modeling Simultaneous Growth of Multiple Hydraulic Fractures and Their Interaction With Natural Fractures[C]. SPE Hydraulic Fracturing Technology Conference, 19-21 January, The Woodlands, Texas, USA, 2009 : 1-7.

[36] Wu K, Olson J. Simultaneous multifracture treatments: fully coupled fluid flow and fracture mechanics for horizontal wells. SPE Journal,2015,20(02):337-346.

[37] Wu K, Olson J.E. Mechanisms of simultaneous hydraulic-fracture propagation from multiple perforation clusters in horizontal wells[J]. SPE Journal. 2015,21(03) , 1000-1008.

[38] Zhao Jinzhou, Xiyu Chen, Yongming Li, Bin Fu,(2016)Simulation of simultaneous propagation of multiple hydraulic fractures in horizontal wells.Journal of Petroleum Science and Engineering. 2016,147: 788800.

[39] GUO Jianchun,YIN Jian,ZHAO Zhihong. FEASIBILITY OF FORMATION OF COMPLEX FRACTURES UNDER CRACKS
INTERFERENCE IN SHALE RESERVOIR FRACTURING[J]. Chinese Journal of Rock Mechanics and Engineering,2014,33(08):15891596. 